\section{Uso da cola de fibrina na prevenção desangramento e hematoma pós-operatório em septoplastias}

\section{Use of fibrin glue in the prevention of postoperative bleeding and hematomas after septoplaties}

\author{
Silvio Caldas Netoํㅜ, Roberto L. Oliveira², Nelson \\ Caldas ${ }^{3}$
}

Resumo / Summary

ntrodução: Entre as complicações da septoplastia, 0 sangramento e o hematoma septal pós-operatório estão entre as mais freqüentes ${ }^{1,2,3}$. Para prevenir tais problemas, a maioria dos cirurgiões ainda faz uso de tamponamentos nasais ou "splints", que tornam o período pós-operatório imediato extremamente desconfortável para o paciente $e^{1,2,4,5,6}$. Este trabalho se propõe a avaliar a eficácia e a segurança do uso da cola biológica nas sep to plastias como profilaxia para essas complicações. Forma de estudo: Clínico prospectivo randomizado. Material emétodo: 0 s auto res observaram 20 pacientes operados de septo plastia entre janeiro e maio de 2002 pelo Real Instituto de Otorrino e Fono, Recife, nos quais foi utilizado selante de fibrina para colar os folhetos septais. Resultados: Nenhum caso de hematoma septal ou epistaxe pós-operatórios foi observado entre os pacientes estudados. Nenhuma complicação intra ou pós-operatória foi relacionada ao uso da cola. Conclusões: A cola de fibrina mostrou ser uma substância eficaz na prevenção das complicações em questão, assim como bem tolerada pelos tecidos das cavidades nasais. Além disso, o recurso assegurou um pós-operatório muito mais tranqüilo e confortável para os pacientes do que o que se costuma observar em pacientes com tampões nasais ou "splints".
Palavras-chave: septoplastia, cola de fibrina, complicações. Key words: septoplasty, fibrin glue, complications.

ntroduction: Among the complications of septoplaty, postoperative septal bleeding and hematoma are some of the most frequent. In order to avoid such problems, most surgeons still use nasal packing and/or splints that make the postoperative period extremely unpleasant. The purpose of this paper is to evaluate the efficacy and safety of fibrin glue in septoplasties for prophylaxis of these complications. Study design: Clinical prospective randomized. Material and method: We observed 20 patients who underwent septoplaties from January to May, 2002, at the Real Instituto de 0 torrino e Fono, in whom we used fibrin glue, in order so seal the septal flaps. Results: No case of septal bleeding or hematoma was noticed and no other complications occurred that could have been associated to the fibrin glue. Conclusions: Fibrin glue proved to be efficacious in preventing such complications and well tolerated by the nasal cavity tissues. Besides, it assured a much more comfortable postoperative period then what we see with nasal packings and splints.

\footnotetext{
${ }^{1}$ D outor em Medicina pela Universidade de São Paulo.

2 Especialista em Otorrinolaringologia.

${ }^{3}$ Prof. Titular de O torrinolaringologia da Universidade Federal de Pernambuco. Instituição:Real Instituto de Otorrino e Fono

Endereço para correspondência: Silvio Caldas Neto - Rua Poeta Zezito Neves, 38, ap. 1801 Recipe - PE - 51020-200

Tel. (0xx81) 3241-0830 - Tel/Fax (0xx81) 3427-4610 - E-mail: caldas@hotlink.com.br

Artigo recebido em 26 de julho de 2002. Artigo aceito em 8 de agosto de 2002.
} 


\section{INTRODUÇÃO}

A septoplastia é um procedimento cirúrgico dirigido à correção dos desvios do septo do nariz. Ela tornou-se uma cirurgia sistematizada a partir de Killian (1905). Desde então, célebres otorrinolaringologistas têm desenvolvido técnicas cirúrgicas diversas, cada uma com suas vantagens e desvantagens, sendo indicadas de forma individual para cada tipo específico de desvio de septo ${ }^{4,7.8}$. A todas elas, porém, é comum a necessidade de descolamento do mucopericôndrio septal. Este descolamento produz ruptura de microcapilares que pode originar sangramentos pós-operatórios, que, por sua vez, podem-se apresentar na forma de epistaxe ou de hematoma de septo. Na literatura, entre as complicações deste tipo de cirurgia, a sinéquia, a epistaxe, o hematoma e a perfuração do septo figuram como as mais freqüentes ${ }^{1,2,3}$. Estes dois últimos podem ser evitados valendo-se de cuidados técnicos intraoperatórios, mas mesmo assim, é comum o relato de sangramentos pós-operatórios por vezes importantes. Por conta deste risco, é prática comum o uso de tampões nasais ou "splints" ao final da cirurgia, que são removidos ainda no pós-operatório imediato ${ }^{1,2,4,5,6}$ em geral, 24 a 48 horas após a cirurgia. Os "splints" e, mais ainda, os tampões nasais costumam representar um grande incômodo pós-operatório, além de perturbar a recuperação da mobilidade ciliar da mucosa nasal. Tal incômodo, às vezes, torna-se, inclusive, motivo de desistência da cirurgia por parte do paciente.

A cola de fibrina tem sido utilizada em diversos tipos de procedimentos nasais sem nenhum relato de complicação relacionada à cola $a^{3,9-12}$. Hayward e Mackay ${ }^{2}$ utilizam-se deste recurso em 30 casos de septoplastia e percebem, no pósoperatório imediato, discreto edema e hiperemia mucosa que supõe ser decorrente de possível reação alérgica à cola. Já Volkov e Radev ${ }^{5}$ usam cola de fibrina em 40 septoplastias, sem relatarem complicações decorrentes disso, e com bons resultados em termos de prevenção de sangramentos (impressão semelhante à de Wüllstein ${ }^{6}$ ).

Com o objetivo de encontrar um meio de manter os folhetos septais coaptados após a cirurgia, sem necessidade de tamponamento ou "splints", utilizamos cola biológica em pacientes operados de septoplastia e avaliamos a evolução pós-operatória imediata destes indivíduos com respeito à ocorrência de complicações.

\section{MATERIAL E MÉTODO}

20 pacientes consecutivamente operados de septoplastia (associada ou não a outros procedimentos intranasais) foram avaliados no período entre janeiro e maio de 2002. A idade dos pacientes variou entre 5 e 62 anos, sendo que apenas um era criança ( 5 anos) e apenas dois tinham mais de 40 anos (um de 50 e outro de 62 anos). 0 restante variou entre 16 e 37 anos. 12 pacientes eram do sexo masculino e 8, do feminino. As cirurgias foram executadas sempre sob anestesia geral e utilizando-se a técnica de ressecção submucosa do desvio osteocartilaginoso, da forma que se segue:

1. Retração mucosa com algodonóide embebido em vasoconstrictor;

2. Infiltração das duas faces do septo do nariz com xylocaína a $2 \%$ com adrenalina 1:100.000;

3. Incisão hemitransfixante em uma das faces septais, a cerca de 0,5 a $1 \mathrm{~cm}$ do bordo caudal do septo, de acordo com as exigências do desvio;

4. Descolamento subpericondral bilateral;

5. Remoção da parte desviada do septo utilizando-se faca de Ballenger e pinças de Takahashi e de Jannsen;

6. Preenchimento do espaço intra-septal com cola de fibrina Beriplast $^{\circledR} \mathrm{P}$, Aventis, com imediata compressão dos folhetos durante al guns segundos;

7. Cobertura da área de incisão do septo com cola de fibrina. Em alguns casos, foi utilizada também sutura desta incisão;

8. Cauterização elétrica monopolar dos pontos de sangramento da mucosa nasal e/ ou sinusal.

O utros procedimentos cirúrgicos foram realizados de acordo com as necessidades de cada caso. A tabela 1 mostra os procedimentos associados realizados nos 20 pacientes

Tabela 1. Relação dos casos e procedimentos realizados

\begin{tabular}{lllll}
\hline & Nome & Idade & Sexo & Procedimentos \\
\hline 1 & JVCMG & 17 & masc & $\mathrm{S}+\mathrm{Tb}$ \\
2 & J SMN & 28 & fem & $\mathrm{S}+\mathrm{Tb}+\mathrm{CMb}+\mathrm{MMb}$ \\
3 & MMCSB & 17 & fem & $\mathrm{S}+\mathrm{Tb}+\mathrm{CMb}+\mathrm{MMu}$ \\
4 & EAP & 25 & fem & $\mathrm{S}+\mathrm{Tb}$ \\
5 & LBS & 62 & masc & $\mathrm{S}+\mathrm{Tb}+\mathrm{CMb}+\mathrm{MMb}+$ \\
& & & & $\mathrm{ETb}+\mathrm{Fb}+\mathrm{ESb}$ \\
6 & JGR & 50 & masc & $\mathrm{S}+\mathrm{Tb}+\mathrm{CMb}+\mathrm{MMb}$ \\
7 & TDF & 16 & masc & $\mathrm{S}+\mathrm{Tb}$ \\
8 & MJ LL & 29 & masc & $\mathrm{S}+\mathrm{Tb}+\mathrm{CMb}+\mathrm{MMb}+\mathrm{Sin}$ \\
9 & JBLN & 20 & masc & $\mathrm{S}+\mathrm{Tb}$ \\
10 & MSF & 29 & masc & $\mathrm{S}+\mathrm{Tb}$ \\
11 & JK & 05 & fem & $\mathrm{S}+\mathrm{Tb}$ \\
12 & MV & 23 & masc & $\mathrm{S}+\mathrm{Tb}$ \\
13 & HJT & 25 & masc & $\mathrm{S}+\mathrm{Tb}$ \\
14 & LSS & 32 & masc & $\mathrm{S}+\mathrm{Tb}$ \\
15 & EAM & 36 & masc & $\mathrm{S}+\mathrm{Tb}$ \\
16 & SRB & 37 & fem & $\mathrm{S}+\mathrm{Tu}$ \\
17 & GRPSB & 36 & masc & $\mathrm{S}+\mathrm{Tb}+\mathrm{CMu}$ \\
18 & AJH & 22 & fem & $\mathrm{S}+\mathrm{Tb}$ \\
19 & EFS & 32 & fem & $\mathrm{S}+\mathrm{Tb}$ \\
20 & AMS & 25 & fem & $\mathrm{S}+\mathrm{Tb}$ \\
\hline
\end{tabular}

$\mathrm{S}=$ septoplastia; $\mathrm{Tb}=$ turbinectomia bilateral; $\mathrm{Tu}=$ turbinectomia unilateral; $\mathrm{CMb}=$ conchotomia média bilateral; $\mathrm{CMu}=$ conchotomia média unilateral; $\mathrm{MMb}=$ meatotomia média bilateral; $\mathrm{MMu}=$ meatotomia média unilateral; $\mathrm{ETb}=$ etmoidectomia bilateral; $\mathrm{Fb}=$ frontotomia bilateral; $\mathrm{ESb}=$ esfenotomia bilateral; $\operatorname{Sin}=$ remoção de sinéquia 
do estudo. Estes outros procedimentos foram feitos seguindo os métodos já bem padronizados de cirurgia endonasal, utilizando-se videoendoscopia e/ou microscopia.

\section{RESULTADOS}

Dos 20 pacientes operados, nenhum apresentou, no pós-operatório imediato, qualquer sinal de hematoma septal, nem tampouco sangramento pós-operatório importante e, por tanto, em nenhum caso foi necessário tamponamento nasal pós-operatório. Na primeira avaliação, feita 1 a 3 dias após o procedimento, o septo nasal encontrava-se com seus folhetos bem coaptados.

Quanto ao resultado funcional, todos os casos apresentaram grande melhora da função respiratória nasal já a partir do dia da intervenção. Esta função piorou após as primeiras 24 horas por conta de edema das conchas nasais, bem como acúmulo de secreção, fibrina e crostas, porém tal condição reverteu logo nas primeiras revisões.

Não houve nenhum caso de outros tipos de complicações, como formação de sinéquias, perfuração septal, abscesso s ou outras.

\section{DISCUSSÃO}

Sabemos que a cirurgia da obstrução nasal, quando realizada de forma correta, tem êxito em virtualmente $100 \%$. Entretanto dois fatores contribuem para que muitos pacientes recusem este tipo de tratamento. Um deles é o fato de que a obstrução nasal, particularmente no adulto, não representa risco importante à sua saúde. Em grau variável ela pode, sim, perturbar a qualidade de vida do indivíduo, mas, em realidade, ele sempre terá a opção de conviver com 0 problema e valer-se de medidas de controle clínico, de acordo com a sua vontade. Outro fator é a perspectiva de um período pós-operatório extremamente desagradável, quando há a expectativa de se utilizar tampões ou "splints" nasais.

O tampão é utilizado para comprimir não só o septo, mas também as conchas nasais inferiores, com a intenção de se evitar sangramento pós-operatório. 0 "splint" nasal funciona exclusivamente para comprimir os folhetos do septo nasal, não realizando nenhuma compressão sobre as conchas. Estas medidas têm sido utilizadas desde os primórdios da cirurgia nasal ${ }^{4}$ e costumam trazer enorme desconforto (sobretudo o tampão) para o paciente, além de atrasar a recuperação da função mucociliar e, com isso, elevar o número de complicações infecciosas. ${ }^{12}$ Entretanto tem-se percebido ao longo dos anos uma diminuição progressiva no tempo de tamponamento e diversos grupos em todo 0 mundo já têm abandonado o uso destes recursos, com índices de sangramento pós-operatório semelhantes aos encontrados com o uso dos mesmos. Provavelmente o domínio das técnicas microendoscópicas de cirurgia endonasal, bem como a utilização de microcautérios mais eficientes tenha contribuído com a redução do temor dos cirurgiões nasais em relação a essas complicações.

Todavia, quando não são utilizadas essas medidas, pode surgir hematoma septal por conta de sangramento, ainda que de pequena monta, entre os folhetos septais. Em geral esses hematomas têm pouco débito e são totalmente reabsorvidos ao cabo de alguns dias. Porém até que se resolvam, atrapalham a evolução pós-operatória, prejudicam a retomada da função mucociliar nasal e trazem incômodo respiratório para o paciente. Além disso, em alguns poucos casos, podem infectar-se e originar abscessos septais e uma cascata de complicações bastante perigosas.

A cola biológica tem sido usada em vários procedimentos cirúrgicos nasais, $, 10,3,11$ inclusive em septoplastias e turbinectomias, ${ }^{2,5,6}$ e já demonstrou ser bem tolerada pelos tecidos desta região, sem que nenhuma complicação tenha sido atribuída de forma inconteste ao seu emprego.

O selante de fibrina usado neste trabalho é um composto de Fibrinogênio, Trombina e Fator XIII humanos, Agente Antifibrinolítico bovino e Cloreto de Cálcio ${ }^{13}$. Tem ação hemostática e adesiva, reproduzindo os passos finais da cascata de coagulação fisiológica, formando um coágulo de fibrina estável. 0 coágulo é degradado naturalmente ao cabo de alguns dias ou semanas, por ação de enzimas fibrinolíticas. Muitos poucos relatos têm sido feitos de reação alérgica a essa substância e apenas um caso suspeito de transmissão de infecção viral pela cola.

Em todos os casos aqui ap resentados foi utilizada a cola biológica para colagem dos folhetos septais ao final da septoplastia. A cola só foi utilizada para este fim, não sendo utilizada para hemostasia de cornetos ou cavidades sinusais nos casos de outros procedimentos associados. Esta hemostasia foi levada a cabo por meio de cauterização criteriosa, sob visão microscópica ou endoscópica, dos pontos de sangramento da mucosa. 0 uso da cola do espaço intraseptal mostrou-se fácil e rápido, exigindo apenas alguns segundos de compressão do septo para que uma colagem se fizesse adequadamente. Raramente mais do que $1 \mathrm{ml}$ de cola foi necessário para colar toda a porção descolada do septo.

Procuramos fazer a primeira revisão pós-operatória 24 a 72 horas após o procedimento para que pudéssemos flagrar qualquer sinal de hematoma septal antes de uma possível reabsorção do mesmo. Em nenhum dos casos percebemos formação de abscesso ou sangramento septal pós-operatório, o que nos levou a acreditar que a cola biológica é um ótimo substituto para o tampão e o "splint" nasal na prevenção dessas complicações, além de assegurar um período pós-operatório imediato muito mais agradável para o paciente.

Observamos também que, em dois casos ( 4 e 12) em que não se utilizou sutura da incisão septal, ocorreu pequena retração e engrossamento do lábio interno desta incisão, o que causou um pequeno estreitamento da fossa 
nasal correspondente. Isto não causou desconforto respiratório para os pacientes, porém, causou-nos a impressão de que a cola biológica talvez não substitua bem a sutura do septo, podendo eventualmente ser causa de insucessos funcionais em fossas nasais mais estreitas.

Em outro caso (5), o desvio septal era extremamente severo e sinuoso, havendo laceração importante do mucopericôndrio bilateralmente, porém não ocorreu sangramento pós-operatório nem perfuração septal, o que, muito embora se trate de um caso isolado, faz-nos especular no interesse do uso da cola também na prevenção da perfuração.

No caso 11, de 5 anos de idade, o recurso da cola mostrou-se particularmente mais importante, pois evitou não só um pós-operatório especialmente desconfortável por tratar-se de criança, como também dispensou procedimentos de retirada de tampão ou "splint", que, nessa faixa de idade, tornam-se mais sofridos ainda.

\section{CONCLUSÕES}

O uso da cola biológica no espaço intra-septal nas cirurgias de septoplastia mostrou ser bastante eficaz na prevenção de hematoma de septo e epistaxe pósoperatórios e garantiu uma recuperação tranqüila e confortável para os pacientes do estudo, demonstrando ser especialmente útil em crianças.

Não houve, nos pacientes estudados, nenhuma complicação intra ou pós-operatória que pudesse ser atribuída ao uso da cola biológica.

\section{REFERÊNCIASBIBUOGRÁFICAS}

1. Eckel W. Tratamiento quirúrgico de las inflamaciones de las fossas nasales y de los senos paransales. In: Tratado de Otorrinolaringologia, Tomo I, Barcelona: Editora Cientifico-Medica; 1969. p.30763.

2. Hayward PJ, Mackay IS. Fibrin glue in nasal septal surgery. J Laryngol Otol 1987;101(2):133-8.

3. Skevas A, Gosepath. [Contribution to the closure of septal perforations (author's transl)] Laryngol Rhinol Otol (Stuttg) 1975;54(6):466-9.

4. Killiam G. The submucous window resection of the nasal septum. Ann Otol 1905;14:363.

5. Volkov A, Radev I. [The use of autologous fibrin adhesive in septoplasty]. Vestn Otorinolaringol Jan-Feb 1996;(1):45-7.

6. Wüllstein SR. [Septoplasty without postoperative nasal packing. Mucosal repair of the upper airway with human biologica glue (author's transl)]. HNO 1979;27(9):322-4.

7. Cottle M. Concepts of nasal physiology as related to nasal surgey. Arch Otolaryngol 1960;72:11.

8. Metzenbaum M. Replacement of the lower end of the dislocated septal cartilage versus submucous ressection of the dislocated end of the septal cartilage. Arch Otolaryngol 1929;9:282.

9. Bertrand B, Doyen A, Eloy P. Triosite implants and fibrin glue in the treatment of atrophic rhinitis: technique and results. Laryngoscope 1996 May;106(5 Pt 1):652-7.

10. Cappabianca P, Cavallo LM, Mariniello G, de Divitis O, Romero $A D$, de Dovitiis E. Easy sellar reconstruction in endoscopic endonasal transsphenoidal surgery with polyester-silicone dural substitute and fibrin glue: technical note. Neurosurgery 2001;49(2):473-5.

11. Wax MK, Ramadan HH, Ortiz O, Wetmore SJ. Contemporary management of cerebrospinal fluid rhinorrhea. Otolaryngol Head Neck Surg 1997;116(4):442-9.

12. Weber R, Keerl R, Draf W, Schick B, Mosler P, Saha A. Management of dural lesions occurring during endonasal sinus surgery. Arch Otolaryngol Head Neck Surg 1996;122(7):732-6. 